XLIX SIR National Congress, Milano, 2012.

\title{
Efficacy of bosentan in the treatment of Raynaud's phenomenon in patients with systemic sclerosis never treated with prostanoids
}

\author{
S. Parisi, M. Bruzzone, C. Centanaro Di Vittorio, A. Laganà, \\ C.L. Peroni, E. Fusaro \\ Struttura Complessa di Reumatologia, A.O. Città della Salute e della Scienza di Torino, Italy
}

\section{SUMMARY}

The objective of this study was to evaluate the efficacy of the endothelin receptor antagonist, bosentan, in patients with Raynaud's phenomenon secondary to systemic sclerosis never treated with prostanoids and without digital ulcers.

The study design is a preliminary, prospective open label trial. The patients recruited took one $62.5 \mathrm{mg}$ dose of bosentan twice daily for 4 weeks, followed by $125 \mathrm{mg}$ twice daily for 24 weeks.

Of the 10 patients recruited, all completed the study. The reduction in Raynaud's phenomenon attacks at week 24 from the baseline was statistically significant $(\Delta-1.3, \mathrm{P}=0.0126)$. The Raynaud's condition score showed a statistically significant improvement $(\Delta-1.4, \mathrm{P}=0.0279)$, as did the visual analog pain scale $(\Delta-1.5, \mathrm{P}=0.0016)$ at the $24^{\text {th }}$ week.

Bosentan appears to be effective and may be a valid alternative for the treatment of severe secondary Raynaud's phenomenon for patients where prostanoids therapy is contraindicated or refused.

Key words: Systemic sclerosis, Raynaud's phenomenon, Endothelin receptor antagonist, Bosentan, Raynaud's condition score.

Reumatismo, 2013; 65 (6): 286-291

\section{INTRODUCTION}

R aynaud's phenomenon (RP) is a paroxystic vasospastic event triggered by cold or emotional states and characterized, in its classic triphasic expression, by pallor (ischaemic phase), followed by cyanosis (asphyctic phase) and lastly redness (reactive hyperaemia phase). There may also be co-existing torpor and paraesthesia. The hands are the most frequently affected sites, but the feet, the auricular pavilions, nose and tongue may also be involved (1). In the majority of cases, this is a primitive phenomenon, not associated with any disease. In a small percentage, it precedes and/or accompanies diseases of the connective tissue, particularly, systemic sclerosis (SSc). In these cases it is defined as secondary Raynaud's phenomenon (2).

While primary RP is characterised by a vasospastic condition that lead to a reduced reactivity to thermal stimuli and never evolves into trophic damage, the RP secondary to SSc is characterised by an initial vasospastic phase which evolves into intraluminal tissue proliferation, determining a process of tissue ischemia of the arterioles involved (3). Moreover, RP in SSc patients, often influences the onset of trophic alterations to the fingertips in the form of necrosis, sloughs, ulcers and residual scarring which are subject to infections and, in more severe cases, even amputation. They have a deeply negative effect on the quality of life. RP and SSc present a physiopathological mechanism, which is still not completely clear today. Several studies have highlighted endothelial damage and alterations in the proliferation of vascular structures, with unbalance of factors regulating vascular dilatation and vascular constriction, in favour of the latter. A very important role appears to be played 
by endothelin (ET-1), a molecule present in extremely high plasma concentration in these patients and which has a powerful vascular constrictive action (4). Traditional treatment of RP in SSc consists of the use of calcium-antagonists and prostanoids (5). Over recent years, the scientific community has focused on some drugs belonging to the endothelin receptor antagonist category, which have given excellent results for the treatment of pulmonary hypertension and (as in the case of bosentan) in the treatment and prevention of digital ulcers (6). In patients with SSc and RP without digital ulcers not responding to traditional therapies, some symptoms (7).

The aim of the study was to assess the efficacy (in terms of improved visual analog pain scale (VAS), RP attacks frequency and Raynaud's condition score (RCS)) of the endothelin receptor antagonist, bosentan, in patients with RP secondary to SSc, without digital ulcers, never treated with prostanoids.

\section{MATERIALS AND METHODS}

Ten female patients were recruited, aged between 36 and 68 (mean 51.8 years), affected with SSc according to the American College of Rheumatology Criteria (8), and who had presented numerous attacks of RP during the day. We evaluated the data related to Raynaud's phenomenon in the previous 6 months, especially the average of the number of daily attacks (median value 3.40). The same sample of patients was used as a case and as a control. Patients with primary RP not associated with SSc and patients with digital ulcers were excluded from the study in order not to compromise the assessment of VAS pain and RCS. Patients that presented blood alterations and cardiovascular, liver or kidney failure were also excluded. Furthermore, the recruited patients had exclusively undergone calcium-antagonist therapy for the RP (nifedipine, amlodipine, lacidipine administered up to the maximum dose allowed and/or tolerated).

They had never undergone endothelin re- ceptor antagonist therapy, prostanoid therapy for personal reasons (logistic issues related to the transport distance) or having been excluded from it due to contraindications (heart arrhythmia, valvulopathy, unstable angina and within 6 months of myocardial infarction) or 5-phosphodiesterase inhibitor therapy.

Women of childbearing potential were required to have a negative pregnancy test before study initiation and apply effective contraceptive methods. The off-label use of bosentan was authorised by the Local Health Authority, after presentation of documentation supporting the treatment. All patients were given a detailed explanation of the study and their informed consent was obtained. Recruitment for the prospective study was carried out in September 2009 , that means before colder months, in order to place more attention on Raynaud's phenomenon and monitoring it more objectively, during the coldest period of the year (Figure 1). The analysis and follow up was performed until March 2010. The patients took one $62.5 \mathrm{mg}$ tablet of bosentan twice a day during the first month, then one $125 \mathrm{mg}$ tablet twice a day. Visits were planned at 4-week intervals and during each visit the patients showed to the physician to inspection a personal diary, where they indicated:

- Date of the event (RP);

- Location: hands, feet, ears, nose, other;

- Duration: minutes;

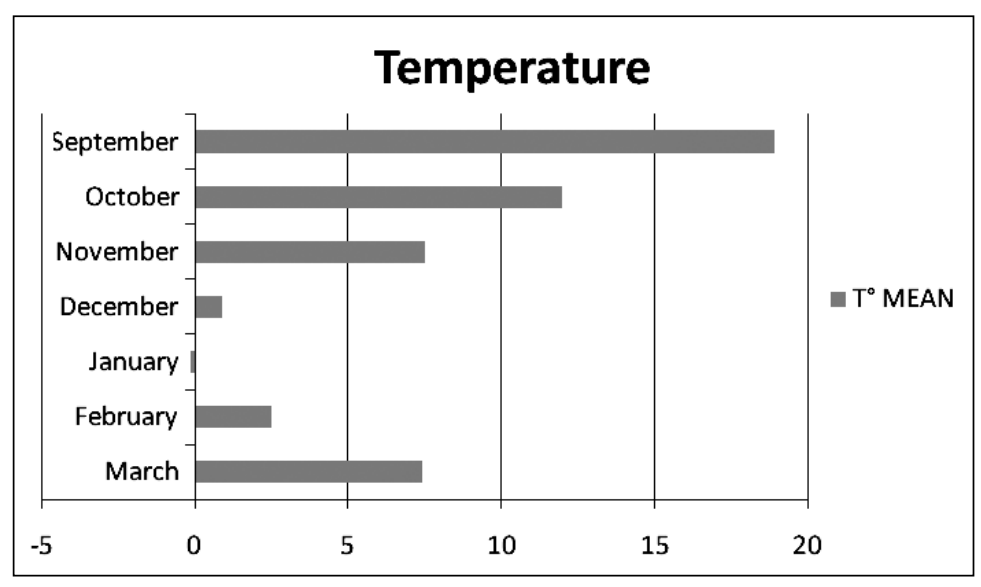

Figure 1 - The mean changes in temperature $\left(T^{\circ}\right.$ Celsius), September 2009 to March 2010. 
- RCS: Limitations on daily activities on a scale of 1 to 10 ( 0 points: subject did not feel handicapped, 10 points: subject felt extremely handicapped by RP);

- VAS pain scale (1-10): indicating 1 as minimum pain and 10 as maximum pain;

- Number of daily attacks;

- Appearance of digital ulcers (Date).

At each visit, a blood sample was taken for routine analysis and a pregnancy test in women with childbearing potential was performed. Liver aminotransferase values (AST, ALT) were also evaluated each month to check the tolerance to the drug. At baseline and at 24 weeks, patients underwent videocapillaroscopy to identify the type of scleroderma pattern and its possible changes (9). At the same time, several parameters for disease activity and organ involvement were evaluated: at weeks 12 and 24 all patients undergone blood tests, to analyse NT-proBNP and troponin, and instrumental tests such as spirometry (FVC e DLCO), echocardiographic assessment with pulmonary arterial pressure, six minute walking test and modified Rodnan skin score (MRSS). To evaluate the degree of disability, all patients were assessed with the scleroderma HAQ disability index (HAQ-DI) at 0, 12 and 24 weeks (10).

\section{Statistical analysis}

The statistical analysis was performed using SPSS statistical software (for Windows, version 16.0) and MINI-TAB (for Windows, version 14.0). The data were expressed as means.

\section{RESULTS}

All ten patients enrolled have completed the study. Mean age was 51.8 years, $60 \%$ presented SSc in limited form and $40 \%$ in diffuse form, the mean duration of scleroderma was 6.1 years and mean duration of RP of 12.2 years. $60 \%$ of the patients were SCL-70 positive, while $40 \%$ were anticentromere positive. At videocapillaroscopy examination, $40 \%$ presented an early scleroderma pattern (with mean of SSc duration $2.5 \pm 0.58$ ), while $60 \%$ presented the active type (with mean of SSc duration 8.5 \pm 1.87 ) (Tab. I and II).

The reduction in RP attacks at week 24 from the baseline (RP attacks baseline median $=3 ; 24^{\text {th }}$ week $=2$ ) was statistically significant $(\Delta-1.3 p=0.0126) 95 \% \mathrm{CI}$ (Table III and Figure 2A) and the improvement was more evident in patient with scleroderma pattern active (Table III). The duration of RP was reduced, but the decrease was not statistically significant $(\Delta-14.5 / \mathrm{P}$ $0.117495 \%$ CI; Table III) and also in this case the improvement was more evident in patient with scleroderma pattern $a c$ tive (Table II). The RCS (median baseline $=5.5 ; 24^{\text {th }}$ week $=4$ ) showed a statistically significant improvement $(\Delta-1.4 / \mathrm{P} \quad 0.0279$ 95\% CI; Table 3 and Figure 2B), as did the VAS pain $(\Delta-1.5 / \mathrm{P} 0.001695 \% \mathrm{CI}$; Table III and Figure 2C) at the $24^{\text {th }}$ week. Lung function (FVC, DLCO, 6MWT) and heart function (echocardiogram, Nt-proBNP, troponin) did not show significant modifica-

Table I - Details of the demographic and clinical characteristics of patients (10 female).

\begin{tabular}{|l|l|}
\hline Characteristics & Results \\
\hline Age, mean \pm SD years & $51.8 \pm 11.4$ \\
\hline RP duration, mean \pm SD years & $12.2 \pm 4.8$ \\
\hline $\begin{array}{l}\text { SSc duration since diagnosis, mean } \pm \text { SD } \\
\text { years }\end{array}$ & $6.1 \pm 3.4$ \\
\hline Diffuse cutaneous SSc, $\%$ & 40 \\
\hline Limited cutaneous SSc, \% & 60 \\
\hline Positive for SCL-70 antibodies, \% & 60 \\
\hline Positive for anticentromere antibodies, $\%$ & 40 \\
\hline Capillaroscopy pattern early, \% & 40 \\
\hline Capillaroscopy pattern active, \% & 60 \\
\hline
\end{tabular}

$\mathrm{SD}$, standard deviation; RP, Raynaud's phenomenon; SSc, systemic sclerosis.

Table II - Details of the videocapillaroscopy and clinical characteristics of patients.

\begin{tabular}{|l|l|l|}
\hline $\begin{array}{l}\text { Videocapillaroscopic } \\
\text { pattern }\end{array}$ & Early & Active \\
\hline $\begin{array}{l}\text { SSc duration since } \\
\text { diagnosis, mean } \pm \text { SD } \\
\text { years }\end{array}$ & $2.5 \pm 0.58$ & $8.5 \pm 1.87$ \\
\hline $\begin{array}{l}\text { Improvement RP daily } \\
\text { attack frequency, } \Delta \text { num }\end{array}$ & $-1 \pm 0.71$ & $-1.5 \pm 1.06$ \\
\hline $\begin{array}{l}\text { Improvement RP attack } \\
\text { duration, } \Delta \text { min }\end{array}$ & $-10.05 \pm 7.07$ & $-17.5 \pm 12.37$ \\
\hline
\end{tabular}


Table III - Mean changes from the baseline values.

\begin{tabular}{|l|l|l|l|}
\hline Measurement & Baseline & 24th week & P-value \\
\hline Liver aminotransferase AST, U/L & $22.40(\mathrm{SD} \pm 6.28)$ & $24.10(\mathrm{SD} \pm 5.92)$ & $\mathrm{ns}$ \\
\hline Liver aminotransferase ALT, U/L & $22.10(\mathrm{SD} \pm 6.81)$ & $19.60(\mathrm{SD} \pm 6.79)$ & $\mathrm{ns}$ \\
\hline $\mathrm{FVC}, \%$ & $102.90(\mathrm{SD} \pm 16.03)$ & $99.80(\mathrm{SD} \pm 12.25)$ & $\mathrm{ns}$ \\
\hline DLCO, $\%$ & $87.90(\mathrm{SD} \pm 10.69)$ & $89.60(\mathrm{SD} \pm 8.98)$ & $\mathrm{ns}$ \\
\hline PAP, $\mathrm{mmHg}$ & $28.60(\mathrm{SD} \pm 3.69)$ & $28.50(\mathrm{SD} \pm 2.55)$ & $\mathrm{ns}$ \\
\hline Nt-proBNP, pg/mL & $117.60(\mathrm{SD} \pm 71.99)$ & $109.00(\mathrm{SD} \pm 61.14)$ & $\mathrm{ns}$ \\
\hline Troponin, $\mathrm{ng} / \mathrm{mL}$ & $<0.01(\mathrm{SD} \pm 0)$ & $<0.01(\mathrm{SD} \pm 0)$ & $\mathrm{ns}$ \\
\hline SaO,$\%$ & $96.40(\mathrm{SD} \pm 0.84)$ & $96.80(\mathrm{SD} \pm 0.79)$ & $\mathrm{ns}$ \\
\hline Distance walked in 6 min, $\%$ & $102.80(\mathrm{SD} \pm 7.16)$ & $104.40(\mathrm{SD} \pm 8.28)$ & $\mathrm{ns}$ \\
\hline RP daily attack frequency, num & $3.40(\mathrm{SD} \pm 1.58)$ & $2.10(\mathrm{SD} \pm 0.74)$ & $\mathbf{0 . 0 1 2 6}$ \\
\hline RP attack duration, min & $60.50(\mathrm{SD} \pm 21.79)$ & $46.00(\mathrm{SD} \pm 15.6)$ & $\mathrm{ns}$ \\
\hline RCS $(1-10)$ & $5.50(\mathrm{SD} \pm 1.51)$ & $4.10(\mathrm{SD} \pm 0.57)$ & $\mathbf{0 . 0 2 7 9}$ \\
\hline VAS pain scale, $(1-10)$ & $6.00(\mathrm{SD} \pm 1.05)$ & $4.50(\mathrm{SD} \pm 0.53)$ & $\mathbf{0 . 0 0 1 6}$ \\
\hline MRSS & $9.00(\mathrm{SD} \pm 2.58)$ & $8.30(\mathrm{SD} \pm 2.11)$ & $\mathrm{ns}$ \\
\hline HAQ-DI & $0.70(\mathrm{SD} \pm 0.21)$ & $0.60(\mathrm{SD} \pm 0.19)$ & $\mathrm{ns}$ \\
\hline
\end{tabular}

AST, aspartate aminotransferase; SD, standard deviation; ns, not significant; ALT, alanine transaminase; FVC, forced vital capacity; DLCO, diffusion lung capacity for carbon monoxide; PAP, mean pulmonary arterial pressure; SaO2, arterial oxygen saturation; RP, Raynaud's phenomenon; RCS, Raynaud's condition score; VAS, visual analog scale; MRSS, modified Rodnan skin score; HAQ-DI: scleroderma health assessment questionnaire disability index.

tions, with constant values maintained in all patients throughout the study (Table III). The MRSS presented no substantial improvements, as did the HAQ-DI (Table III). Videocapillaroscopic evaluation showed no statistically significant changes, since patterns were stationary. No patients developed digital ulcers during the follow up. There were not adverse events during the study, especially no transaminase increase.

\section{DISCUSSION}

This is the first, preliminary, non-controlled cohort study with patients treated with bosentan who have never undergone prostanoid therapy for RP. Bosentan was shown to be effective to reduce (statistically significant) RCS, the number of RP attacks and VAS. Several reports described the successful, but non-blinded approach of bosentan in the treatment of digital ulcers in SSc patients (11-13). Thus, this preliminary study it's restricted by its limitations. It is too underpowered to detect small treatment effect. Nevertheless as previously shown by other authors, our data highlighted a statistically significant im- provement of RP $(14,15)$. Similarly, one case report revealed improvement in pain, number and severity of RP attacks in two SSc patients without pre-existing digital ulcers (13), while other studies failed to document any beneficial effect on VAS, RP or development of digital ulcers $(7,16-18)$. These lesions determine patient worsening of the quality of life, not only in terms of pain, but also due to the extreme difficulty in performing normal daily activities. Another interesting aspect, although not statistically significant, is the HAQ-DI disability assessment improvement. Number of attacks and duration of Raynaud's phenomenon were greater in patients with an active capillaroscopic condition and longer duration of disease, probably due to progressive endothelial damage. No patient were found to present late pattern microangiopaty even if SCL 70 antibodies frequently associate with advanced capillary alterations, a fact that could be due to selection bias.

Our results underline the efficacy of these endothelin receptor antagonist drugs on vasospastic phenomena, which confirm the fundamental role of endothelin in the pathogenesis of SSc, even if the data remain still unclear. 


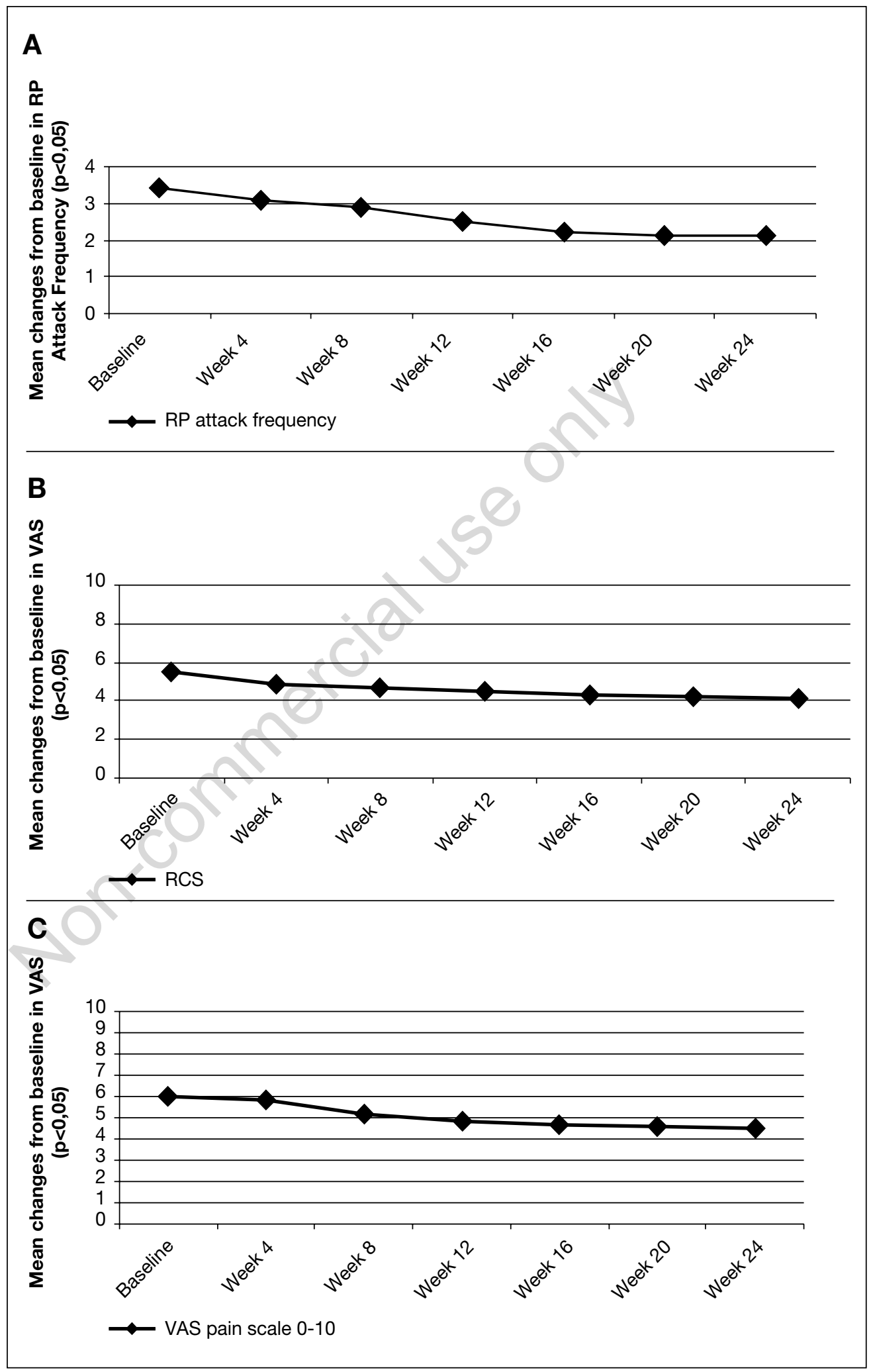

Figure 2 - The mean changes from baseline of Raynaud's phenomenon attack frequency (A), Raynaud's condition score (B) and visual analog scale pain (C) at different control visits. 


\section{CONCLUSIONS}

In conclusion, the use of bosentan in the treatment of Secondary Raynaud's Phenomenon in patients not presenting digital ulcers appears to be effective, with good tolerability and with no adverse events. The results highlighted several phenomena, which deserve further analysis with a wider sample base. Indeed, we believe that, at least for those patients where prostanoids therapy is contraindicated or refused, bosentan may be a valid alternative for the treatment of severe RP.

Conflict of interests: the authors declare no potential conflict of interests.

\section{REFERENCES}

1. Kahaleh MB. Raynaud phenomenon and the vascular disease in scleroderma. Curr Opin Rheumatol. 2004; 16: 718-22.

2. Wigley FM. Clinical practice. Raynaud's phenomenon. N Engl J Med. 2002; 347: 1001-8.

3. Herrick AL. Pathogenesis of Raynaud's phenomenon. Rheumatology 2005; 44: 587-96.

4. Mayes MD. Endothelin and endothelin receptor antagonists in systemic rheumatic disease. Arthritis Rheum. 2003; 48: 1190-9.

5. Black CM, Denton CP. The management of systemic sclerosis. Br J Rheumatol. 1995; 34 : 3-7.

6. Korn JH, Mayes M, Matucci Cerinic M, Rainisio M, Pope J, Hachulla E, et al. Digital ulcers in systemic sclerosis: prevention by treatment with bosentan, an oral endothelin receptor antagonist. Arthritis Rheum. 2004; 50: 3985-93.

7. Nguyen VA, Eisendle K, Gruber I, Hugl B, Reider D, Reider N. Effect of the dual endothelin receptor antagonist bosentan on Raynaud's phenomenon secondary to systemic sclerosis: a double-blind prospective, randomized, placebo-controlled pilot study. Rheumatology (Oxford) 2010; 49: 583-7.

8. Subcommittee for Scleroderma Criteria of the American Rheumatism Association Diagnostic and Therapeutic Criteria Committee. Preliminary criteria for the classification of systemic sclerosis (scleroderma). Arthritis Rheum. 1980; 23: 581-90.

9. Cutolo M, Sulli A, Pizzorni C, Accardo S. Nailfold videocapillaroscopy assessment of microvascular damage in systemic sclerosis. J Rheumatol. 2000; 27: 155-60.

10. Merkel PA, Herlyn K, Martin RW, Anderson JJ, Mayes MD, Bell P, et al. Scleroderma Clinical Trials Consortium. Measuting disease activity and functional status patients with scleroderma and Raynaud's phenomenon. Arthritis Rheum. 2002; 46: 2410-20.

11. Ramos-Casals M, Brito-Zerón P, Nardi N, Claver G, Risco G, Parraga FD, et al. Successful treatment of severe Raynaud's phenomenon with bosentan in four patients with systemic sclerosis. Rheumatology 2004; 43: 1454-6.

12. Tillon J, Hervé F, Chevallier D, Muir JF, Levesque H, Marie I. Successful treatment of systemic sclerosis-related digital ulcers and sarcoidosis with endothelin receptor antagonist (bosentan) therapy. Br J Dermatol. 2006; 154: 1000-2.

13. Yu EP, Ostor AJ, Hall FC. Successful treatment with bosentan for severe digital ischaemia in limited cutaneous systemic sclerosis. Ann Rheum Dis. 2007; 66: 1122-3.

14. Launay D, Diot E, Pasquier E, Mouthon L, Boullanger N, Fain O, et al. (Bosentan for treatment of active digital ulcers in patients with systemic sclerosis). Presse Med. 2006; 35: 587-92 (In French).

15. García de la Peña-Lefebvre P, Rodríguez Rubio S, Valero Expósito M, Carmona L, Gámir Gámir ML, Beltrán Gutiérrez J, et al. Longterm experience of bosentan for treating ulcers and healed ulcers in systemic sclerosis patients. Rheumatology 2008; 47: 464-6.

16. Selenko-Gebauer N, Duschek N, Minimair G, Stingl G, Karlhofer F. Successful treatment of patients with severe secondary Raynaud's phenomenon with the endothelin receptor antagonist bosentan. Rheumatology 2006; 45: iii45-8.

17. Moore TL, Vail A, Herrick AL. Assessment of digital vascular structure and function in response to bosentan in patients with systemic sclerosis-related Raynaud's phenomenon. Rheumatology 2007; 46: 363-4.

18. Seilbold JR, Matucci-Cerinic M, Denton CP, Furst DE, Mayer MD, Kramer F, et al. Bosentan reduces the number of new digital ulcers in patients with systemic sclerosis (abstract). Ann Rheum Dis. 2006; 65: 90. 